\title{
Presencia del IAPH en el III Congreso Mundial de Conservación de Metales 2001
}

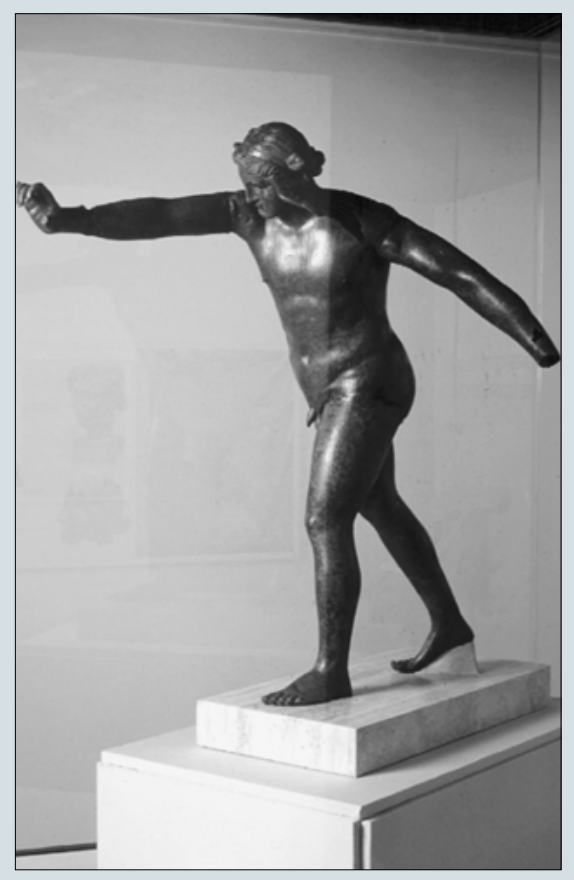

Los días 2-6 de Abril se ha celebrado en Santiago de Chile en la Casa Central, Sala de Honor Universidad de Chile, Av. Libertador B. O'Higgins (Alameda) 1058; el III Congreso Mundial de Conservación de Metales 200 I, organizado por la Universidad de Chile, Facultad de Artes, Departamento de Teoría, conjuntamente con el ICOM-CC Metals Working Group, del cual es Coordinador William Mourey.

Participaron a este Congreso especialistas de más de 20 países, y fueron presentadas 51 ponencias, divididas en cinco bloques temáticos diferentes que son:

- Conservación de metales

- Análisis de los metales y sus productos de corrosión

- Estudios de corrosión y degradación

- Conservación Arqueológica

- electroquímica, inhibidos y Conservación Preventiva

También el Instituto Andaluz del Patrimonio Histórico ha querido estar presente en este Congreso mundial de especialistas en con- servación de metales, enviando una ponencia con el titulo Metodología de investigación, intervención y montaje en la escultura romana en bronce denominada el Hypnos de Almedinilla, realizada por los técnicos que han ejecutado el estudio, la investigación, y la restauración de esta obra que son:

Ana Bouzas Abad, conservadora-restauradora del taller de materiales arqueológicos del $\mathrm{IAPH}$

Raniero Baglioni, asesor técnico en conservación preventiva del IAPH

La gran importancia, que esta restauración ha representado para el IAPH consiste en el hecho de haber podido recuperar para el disfrute publico y para el Patrimonio Histórico Andaluz uno de los bronces romanos de mayor calidad artística y significación histórica y patrimonial.

Para el Instituto Andaluz del Patrimonio Histórico el proyecto ha supuesto la consolidación de una línea de I+D en conservación de metales históricos, iniciada hace cuatro años y de la que han formado parte los proyectos de intervención en la escultura en bronce de Claudio III el Gótico (Togado de Periate) y en el conjunto de herramientas (hierro) procedente de la mina romana del Centenillo, hoy conservadas en el Museo de Cástulo (Jaén) y la gran escultura en bronce de epoca renacentista, el Giraldillo perteneciente a la Catedral de Sevilla.

Las conclusiones que se pueden extraer y que suponen la parte más novedosa de esta intervención de conservación y de restauración son:

- Haber podido investigar en profundidad el estado de conservación de la obra y poder medir las características mecánicas del material que lo constituye.

- Restituir con la intervención de conservación y restauración, la continuidad estructural y estética de la obra que tenia totalmente perdida, después de haber sido tratada en los años 90, cuándo se le practicó una limpieza somera de las capas de concreciones calcáreas y de los productos de corrosión.
- Haber tenido la posibilidad de estudiar, proyectar y realizar un sistema mecánico para el ensamblado reversible de las diferentes piezas fragmentadas que constituyen la escultura.

En el caso que nos ocupa el ensamblado y montaje de la obra, ha supuesto unas de las fases, conjuntamente con la de consolidación del material metálico, el bronce, de mayor importancia, por los problemas que en este caso concreto implicaba para la obra.

A modo de resumen destacamos las principales ventajas metodológicas que este sistema de montaje presenta a la hora de ensamblar y presentar al publico obras escultóricas huecas en metal.

- Reversibilidad total del sistema.

- Inocuidad del sistema y de los elementos empleados respecto al material original.

- Mantenimiento de las piezas ensambladas en las posiciones prefijadas.

- Facilidad de montaje y desmontaje.

- No requiere la realización de ninguna operación que resulte traumática para la obra.

- Bajo coste económico.

Con esta actuación y con su presentación en el Congreso Mundial de Chile, el IAPH ha querido presentar $y$ difundir al mundo especializado una intervención, que tanto desde un punto de vista metodológico, como de la intervención realizada, ha permitido recuperar con éxito y poner en valor para su disfrute publico, de una de las joyas arqueológicas más representativa y desconocida de nuestra región, respetando los principios básicos de la conservación de bienes culturales.

Raniero Baglioni

Ana Bouzas Abad

Centro de Intervención del IAPH 